\section{Vitrectomy for diabetic macular oedema}

DAH Laidlaw

fluorescein angiography; ICG; posterior

vitreous detachment

\section{Introduction}

Working with Schepens in 1998, Nazarallah et $a l^{1}$ published the first data to suggest that the vitreous might play a role in the pathogenesis of diabetic macular oedema (DMO). They examined patients with diabetic retinopathy and found that DMO was present only in $20 \%$ of patients with a PVD compared to $55 \%$ in those with an attached hyaloid.

The second major landmark in the history of vitrectomy for DMO occurred in 1992 when Lewis et $a l^{2}$ described 10 patients who underwent vitrectomy to remove a 'thickened taut glistening posterior hyaloid' (TTPH) in association with impaired vision and DMO. In 8 out of 10 patients, the acuity and macular thickening improved. The authors hypothesised in this pre-OCT era that the hyaloid was exerting tangential traction on the retinal surface, thereby inducing or exacerbating oedema and producing a shallow tractional retinal detachment as part of their clinical syndrome. In addition, they reported that vitrectomy with relief of this traction, resulted in reduction of oedema and visual improvement. (Following the invention of OCT, a group including Lewis imaged patients with DMO and a TTPH. ${ }^{3}$ They confirmed the previous predictions by demonstrating focal vitreoretinal traction associated with surrounding partial posterior hyaloid separation. Furthermore in eight patients, they reported the shallow tractional macular detachment previously predicted by Lewis.) The tractional cause and effect hypothesis advanced by this group is very attractive and appears to fit with the reported anatomical and visual success of vitrectomy in patients with a TTPH. $^{3-7}$
Department of

Ophthalmology, St Thomas Hospital, London, UK

Correspondence:

DAH Laidlaw,

Ophthalmology,

St Thomas' Hospital, Lambeth Palace Road, Lambeth, London SE1 7EH, UK

Tel: + 02079289292 ext 5667;

Fax: + 02079228157.

E-mail: alistair.laidlaw@ gstt.nhs.uk

Received: 21 January 2008 Accepted in revised form: 21 January 2008 Published online: 25 April 2008
Keywords: vitrectomy; diabetic macular oedema; optical coherence tomography; 
The other paper that is frequently cited in the background to vitrectomy for DMO is a natural history study published by Hickichi et $a l^{8}$ in which they reported spontaneous resolution

of DMO in $55 \%$ of eyes that developed a PVD

during follow-up, compared with only $25 \%$ in those that did not.

Various mechanisms by which the vitreous may contribute to the formation of DMO have been postulated. These include vitreomacular traction, which may range from the taut thickened hyaloid described by Lewis et $a l^{2,3,9}$ through partial vitreomacular separation ${ }^{10,11}$ to microtraction resulting from an abnormal PVD resulting in posterior vitreoschisis and a persistent pre-macular vitreous adhesion. ${ }^{12}$ Relief of traction is not the only postulated mechanism for improved structure and function after vitrectomy; Stefansson ${ }^{13,14}$ has long advocated that improved transvitreal oxygenation of the retina may be the causative mechanism. Others have suggested that removal of a growth factor reservoir in the pre-macular hyaloid is important. ${ }^{15}$ It is known that the diabetic vitreous is abnormal with enzyme-mediated vitreous collagen crosslinking and non-enzymatic glycation; with reduced permeability potentially increasing the concentration of a pre-macular growth factor soup. ${ }^{16-18}$

There is now a copious literature on the subject of vitrectomy for DMO, which probably includes more than a thousand eyes ${ }^{2-4,6,7,9-11,15,19-44}$ (this list does not attempt to be exhaustive). Systematic interpretation of this literature is however very hard and the vast majority of these reports would be rejected from a structured systematic review. The reasons for this are that most studies are relatively small and retrospective with differing disease severity and inclusion criteria, variable and incomplete follow-up, and differing outcome measures.

Given the hypothesised importance of vitreomacular traction, few studies have classified their cases on the basis of OCT appearance. DMO is an extremely heterogenous condition, with the reports describing surgery on patients with a taut thickened hyaloid, ${ }^{2,4,5,7}$ epiretinal membrane, ${ }^{11,43}$ and complete PVD formation. ${ }^{11,45}$ In a prospective study of the clinical and OCT features of 140 patients with DMO refractory to laser, we found a clinically and OCT normal hyaloid to be present in two-thirds. ${ }^{11,46}$

Much of the early literature, although uncontrolled, concentrates on patients with DMO in the presence of a taut thickened posterior hyaloid and these reports all suggest benefit in terms of improved acuity and reduced macular thickening. ${ }^{2,4-7,23}$ This is however a rare clinical presentation occurring in just $4 \%$ of eyes in our prevalence study. ${ }^{46}$
Other than macular traction, potentially important predictors of outcome include the duration of macular oedema, extent of previous laser, degree of macular ischaemia, and amount of exudation. Photoreceptor dysfunction following chronic oedema, laser photocoagulation-induced damage and the macular perfusion abnormalities found in diabetic eyes might all limit visual recovery despite resolution of oedema. Cataract formation and/or progression has not been routinely quantified. In addition, the surgery has varied in terms of inclusion of ILM peeling and, when performed, use of vital staining.

These important caveats not withstanding most of the studies have suggested that vitrectomy is an impressively effective treatment in terms of improving macular thickening and visual acuity. As an illustration of this, we recently reviewed the results of 10 prospective studies, which in total included 178 eyes. The results suggest that vitrectomy may be beneficial in terms of visual recovery. 100/178 eyes (56.2\%) demonstrated an acuity improvement of two or more lines at final follow-up. ${ }^{2,29,30,32,39,47-49}$ The proportion of eyes in these studies that improved by more than two lines ranged from 50 to $78 \%$.

There are now six published randomised trials of vitrectomy for $\mathrm{DMO}$, including one performed by our group. ${ }^{15,19,37,41,50,51}$ Our trial included 40 patients ${ }^{19}$ with an attached but otherwise normal posterior hyaloid (ie, no clinical traction or PVD), who were randomised to either more laser or vitrectomy with ILM peeling. We found no clinically or statistically significant difference in acuity or macular thickness reduction between the lasered control and vitrectomy groups at 12 months follow-up. There was also no significant change in either group between baseline and 1-year follow-up. Patel et $a^{34}$ and Kumar et al ${ }^{37,50}$ have also reported no benefit from similar RCTs, which respectively included 20 and 24 patients with an attached but clinically normal posterior hyaloid. Yanyali et $a l^{41}$ has however reported an RCT in which 10 patients with bilateral DMO were randomly assigned to vitrectomy on one eye and no treatment on the fellow eye with 12-month follow-up. There was a mean acuity improvement of just under $2 \log$ MAR lines in the treatment group compared to a $1.5 \log$ MAR line mean deterioration in the controls. In another paired-eye randomised trial of 12 patients by the same author, the eyes randomised to vitrectomy improved by $0.22 \log$ MAR and $210 \mu \mathrm{m}$ from $0.75 \log$ MAR and $439 \mu \mathrm{m}$ whereas the 12 fellow eyes randomised to laser improved by $0.10 \log$ MAR and $29 \mu \mathrm{m}$ from $0.59 \log$ MAR and $407 \mu \mathrm{m}$ respectively. ${ }^{51}$ The numbers in both of these trials are very small and the groups do not appear to be balanced at baseline in terms of acuity; however, statistically and clinically significant changes in acuity 
were found in each study. In an RCT that included 56 eyes reported by Binder's group, 25 eyes were randomised to vitrectomy and 31 into the control group. ${ }^{15}$ This trial reported relatively subtle mean central macular thickness differences between the groups at the 6-month follow-up visit with a $20-\mu \mathrm{m}$ increase in the controls and a comparable decrease in the intervention group from a baseline of $560 \mu \mathrm{m}$. In all, 32\% of controls but only $12 \%$ of the intervention group worsened by $2 \log$ MAR whereas $40 \%$ of those undergoing vitrectomy compared to $10 \%$ of control improved by the same increment. A fundamental principle of a randomised controlled trial is that the groups should differ only in terms of the intervention under scrutiny. The inclusion criteria allowed for patients with up to LOCS grade 3 cataract to be included and cataract surgery was performed on one-third of the intervention group on this basis, but none of the controls underwent such surgery. No allowance was made for this in the analysis. The inclusion criteria may also have selected for a group in whom OCT partial vitreomacular separation was present, as OCT evidence of an adherent hyaloid was an inclusion criterion. The omission of investigation into potential bias induced by the cataract surgery performed in one-third of the intervention group unfortunately casts significant doubt on the trial conclusions.

The importance of OCT imaging is increasingly being recognised and has now revolutionised the clinical analysis of the vitreomacular interface. ${ }^{10,11,52}$ OCT features suggesting vitreoretinal traction may occur in the absence of a clinical TTPH, which is anyway a clinically rare feature. ${ }^{11,46}$ From our prospective study of vitrectomy for $\mathrm{DMO}$ with systematic 1-year follow-up, we found that $15 \%(5 / 33)$ and $24 \%(8 / 33)$ respectively improved or deteriorated by 2 or more ETDRS logMAR lines. Patients were subdivided on the basis of their preoperative OCT scan vitreoretinal interface appearance. The 22 patients who had no OCT macular traction had a respective mean VA deterioration of $-0.11 \log$ MAR and CMT improvement of $-117 \mu \mathrm{m}$. Overall, the 11 patients with vitreomacular traction (ie, TTPH, ERM, and/or OCT signs of traction) had an approximately $1 \log$ MAR line improvement in acuity compared to a one-line deterioration in $\log$ MAR acuity in the 22 patients without any evidence of macular traction. ${ }^{11}$

The findings of this study run parallel to those reported by Massin et $a l^{10}$ who suggested that the benefit of vitrectomy may be confined to patients with OCT signs suggestive of macular traction. They are however at odds with the other prospective data on this subject in which $56 \%$ of reported patients have improved by 2 or more $\log$ MAR or Snellen lines (vs). Included in these reports are the data recently reported by Recchia et $a l^{39}$ in which only 2/11 patients had any OCT signs suggesting macular traction but in which the mean acuity changed over 6 months from 20/352 to 20/119. In addition, Yanyali et $a l^{42}$ have recently reported a prospective series in which none of the 27 patients had OCT evidence of vitreomacular traction. They found a mean acuity improvement of just over $1 \log$ MAR line and a $20 \%$ reduction of central macular thickness occurred in $80 \%$ of patients.

Where results have been compared, there appears to be little benefit or detriment from ILM peeling as part of the procedure. ${ }^{11,53}$

At present, the jury appears to be out on the benefits of vitrectomy for DMO. Most retrospective and prospective uncontrolled studies have suggested that the surgery is beneficial and this is supported by two randomised trials, of which significant bias could be cast on the conclusions of one. Paradoxically, three other randomised trials and a number of other carefully conducted series have found no benefit. It has been suggested that the benefit may be confined to a subgroup of patients with vitreomacular traction evident on OCT; other studies, however, refute this. Hopefully, the evidence will become easier to interpret with the results of further studies such as those being performed by the Diabetic Retinopathy Clinical Research Network (www.drcr.net).

\section{References}

1 Nasrallah FP, Jalkh AE, Van Coppenolle F, Kado M, Trempe CL, McMeel JW et al The role of the vitreous in diabetic macular edema. Ophthalmology 1988; 95(10): 1335-1339.

2 Lewis H, Abrams GW, Blumenkranz MS, Campo RV. Vitrectomy for diabetic macular traction and edema associated with posterior hyaloidal traction. Ophthalmology 1992; 99(5): 753-759.

3 Kaiser PK, Riemann CD, Sears JE, Lewis H. Macular traction detachment and diabetic macular edema associated with posterior hyaloidal traction [see comment]. Am J Ophthalmol 2001; 131(1): 44-49.

4 Pendergast SD. Vitrectomy for diabetic macular edema associated with a taut premacular posterior hyaloid. Curr Opin Ophthalmol 1998; 9(3): 71-75.

5 Pendergast SD, Hassan TS, Williams GA, Cox MS, Margherio RR, Ferrone PJ et al Vitrectomy for diffuse diabetic macular edema associated with a taut premacular posterior hyaloid. Am J Ophthalmol 2000; 130(2): 178-186.

6 van Effenterre G, Guyot-Argenton C, Guiberteau B, Hany I, Lacotte JL. [Macular edema caused by contraction of the posterior hyaloid in diabetic retinopathy. Surgical treatment of a series of 22 cases]. J Fr Optalmol 1993; 16(11): 602-610.

7 Harbour JW, Smiddy WE, Flynn Jr HW, Rubsamen PE. Vitrectomy for diabetic macular edema associated with a thickened and taut posterior hyaloid membrane. Am J Ophthalmol 1996; 121(4): 405-413.

8 Hikichi T, Fujio N, Akiba J, Azuma Y, Takahashi M, Yoshida A. Association between the short-term natural history of diabetic macular edema and the vitreomacular 
relationship in type II diabetes mellitus. Ophthalmology 1997; 104(3): 473-478.

9 Lewis $\mathrm{H}$. The role of vitrectomy in the treatment of diabetic macular edema [comment]. Am J Ophthalmol 2001; 131(1): 123-125.

10 Massin P, Duguid G, Erginay A, Haouchine B, Gaudric A. Optical coherence tomography for evaluating diabetic macular edema before and after vitrectomy. Am J Ophthalmol 2003; 135(2): 169-177.

11 Shah SP, Patel M, Thomas D, Aldington S, Laidlaw DA. Factors predicting outcome of vitrectomy for diabetic macular oedema: results of a prospective study. $\mathrm{Br} \mathrm{J}$ Ophthalmol 2006; 90(1): 33-36.

12 Kishi S, Demaria C, Shimizu K. Vitreous cortex remnants at the fovea after spontaneous vitreous detachment. Int Ophthalmol 1986; 9(4): 253-260.

13 Stefansson E. Ocular oxygenation and the treatment of diabetic retinopathy. Surv Ophthalmol 2006; 51(4): 364-380.

14 Stefansson E. The therapeutic effects of retinal laser treatment and vitrectomy. A theory based on oxygen and vascular physiology. Acta Ophthalmologica Scandinavica 2001; 79(5): 435-440.

15 Stolba U, Binder S, Gruber D, Krebs I, Aggermann T, Neumaier B. Vitrectomy for persistent diffuse diabetic macular edema. Am J Ophthalmol 2005; 140(2): 295-301.

16 Sebag J. Abnormalities of human vitreous structure in diabetes. Graefes Arch Clin Exp Ophthalmol 1993; 231(5): 257-260.

17 Sebag J, Buckingham B, Charles MA, Reiser K. Biochemical abnormalities in vitreous of humans with proliferative diabetic retinopathy. Arch Ophthalmol 1992; 110(10): 1472-1476.

18 Sebag J, Nie S, Reiser K, Charles MA, Yu NT. Raman spectroscopy of human vitreous in proliferative diabetic retinopathy. Investig Ophthalmol Vis Sci 1994; 35(7): 2976-2980.

19 Thomas D, Bunce C, Moorman C, Laidlaw DAH. A randomised controlled feasibility trial of vitrectomy $v$ s laser for diabetic macular oedema. Br J Ophthalmol 2005; 89(1): $81-86$.

20 Tachi N. Surgical management of macular edema. Semin Ophthalmol 1998; 13(1): 20-30.

21 Tachi N, Ogino N. Vitrectomy for diffuse macular edema in cases of diabetic retinopathy. Am J Ophthalmol 1996; 122(2): 258-260.

22 Yang CM. Surgical treatment for severe diabetic macular edema with massive hard exudates. Retina 2000; 20(2): 121-125.

23 Gandorfer A, Messmer EM, Ulbig MW, Kampik A. Resolution of diabetic macular edema after surgical removal of the posterior hyaloid and the inner limiting membrane. Retina 2000; 20(2): 126-133.

24 Otani T, Kishi S. A controlled study of vitrectomy for diabetic macular edema. Am J Ophthalmol 2002; 134(2): 214-219.

25 Amino K, Tanihara H. Vitrectomy combined with phacoemulsification and intraocular lens implantation for diabetic macular edema. Jpn J Ophthalmol 2002; 46(4): 455-459.

26 Ando F, Yasui O, Hirose H, Ohba N. Optic nerve atrophy after vitrectomy with indocyanine green-assisted internal limiting membrane peeling in diffuse diabetic macular edema. Adverse effect of ICG-assisted ILM peeling. Graefes Arch Clin Exp Ophthalmol 2004; 242(12): 995-999.
27 Arrigg PG, Cavallerano J. The role of vitrectomy for diabetic retinopathy. J Am Optom Assoc 1998; 69(11): 733-740.

28 Browning DJ, Fraser CM, Powers ME. Comparison of the magnitude and time course of macular thinning induced by different interventions for diabetic macular edema: implications for sequence of application. Ophthalmology 2006; 113(10): 1713-1719.

29 Giovannini A, Amato G, Mariotti C, Scassellati-Sforzolini B. Optical coherence tomography findings in diabetic macular edema before and after vitrectomy. Ophthalmic Surg Lasers 2000; 31(3): 187-191.

30 Dillinger P, Mester U. Vitrectomy with removal of the internal limiting membrane in chronic diabetic macular oedema. Graefes Arch Clin Exp Ophthalmol 2004; 242(8): 630-637.

31 Higuchi A, Ogata N, Jo N, Wada M, Matsumura M. Pars plana vitrectomy with removal of posterior hyaloid face in treatment of refractory diabetic macular edema resistant to triamcinolone acetonide. Jpn J Ophthalmol 2006; 50(6): 529-531.

32 Jahn CE, Topfner von Schutz K, Richter J, Boller J, Kron M. Improvement of visual acuity in eyes with diabetic macular edema after treatment with pars plana vitrectomy [see comment]. Ophthalmologica 2004; 218(6): 378-384.

33 Kolacny D, Parys-Vanginderdeuren R, Van Lommel A, Stalmans P. Vitrectomy with peeling of the inner limiting membrane for treating diabetic macular edema. Bull Soc Belge Ophtalmol 2005; 296(2): 15-23.

34 La Heij EC, Hendrikse F, Kessels AG, Derhaag PJ. Vitrectomy results in diabetic macular oedema without evident vitreomacular traction. Graefes Arch Clini Exp Ophthalmol 2001; 239(4): 264-270.

35 Lai WW, Mohamed S, Lam DSC. Improvement of visual acuity in eyes with diabetic macular edema after treatment with pars plana vitrectomy.[comment]. Ophthalmologica 2005; 219(3): 189.

36 Micelli Ferrari T, Cardascia N, Durante G, Vetrugno M, Cardia L. Pars plana vitrectomy in diabetic macular edema. Doc Ophthalmol 1999; 97(3-4): 471-474.

37 Patel JI, Hykin PG, Schadt M, Luong V, Bunce C, Fitzke F et al Diabetic macular oedema: pilot randomised trial of pars plana vitrectomy $v$ s macular argon photocoagulation. Eye 2006; 20(8): 873-881.

38 Patel JI, Hykin PG, Schadt M, Luong V, Fitzke F, Gregor ZJ. Pars plana vitrectomy for diabetic macular oedema: OCT and functional correlations. Eye 2006; 20(6): 674-680.

39 Recchia FM, Ruby AJ, Carvalho Recchia CA. Pars plana vitrectomy with removal of the internal limiting membrane in the treatment of persistent diabetic macular edema [see comment]. Am J Ophthalmol 2005; 139(3): 447-454.

40 Rosenblatt BJ, Shah GK, Sharma S, Bakal J. Pars plana vitrectomy with internal limiting membranectomy for refractory diabetic macular edema without a taut posterior hyaloid. Graefes Arch Clin Exp Ophthalmol 2005; 243(1): 20-25.

41 Yanyali A, Horozoglu F, Celik E, Ercalik Y, Nohutcu AF. Pars plana vitrectomy and removal of the internal limiting membrane in diabetic macular edema unresponsive to grid laser photocoagulation. Eur J Ophthalmol 2006; 16(4): 573-581.

42 Yanyali A, Horozoglu F, Celik E, Nohutcu AF. Long-term outcomes of pars plana vitrectomy with internal limiting membrane removal in diabetic macular edema. Retina 2007; 27(5): 557-566. 
43 Yamamoto T, Akabane N, Takeuchi S. Vitrectomy for diabetic macular edema: the role of posterior vitreous detachment and epimacular membrane. Am J Ophthalmol 2001; 132(3): 369-377.

44 Yamamoto T, Hitani K, Sato Y, Yamashita H, Takeuchi S. Vitrectomy for diabetic macular edema with and without internal limiting membrane removal [see comment]. Ophthalmologica 2005; 219(4): 206-213.

45 Yamamoto S, Yamamoto T, Ogata K, Hoshino A, Sato E, Mizunoya S. Morphological and functional changes of the macula after vitrectomy and creation of posterior vitreous detachment in eyes with diabetic macular edema. Doc Ophthalmol 2004; 109(3): 249-253.

46 Thomas D, Bunce C, Moorman C, Laidlaw AH. Frequency and associations of a taut thickened posterior hyaloid, partial vitreomacular separation, and subretinal fluid in patients with diabetic macular edema. Retina 2005; 25(7): 883-888.

47 Otani T, Kishi S. Tomographic assessment of vitreous surgery for diabetic macular edema [see comment]. Am J Ophthalmol 2000; 129(4): 487-494.

48 Avci R, Avci B, Kaderli B, Cavusoglu I. A new surgical approach for indocyanine green-assisted internal limiting membrane peeling. Ophthalmic Surg Lasers Imaging 2004; 35(4): 292-297.

49 Otani T, Kishi S. Tomographic findings of foveal hard exudates in diabetic macular edema. Am J Ophthalmol 2001; 131(1): 50-54.

50 Kumar A, Sinha S, Azad R, Sharma YR, Vohra R. Comparative evaluation of vitrectomy and dye-enhanced ILM peel with grid laser in diffuse diabetic macular edema. Graefes Arch Clin Exp Ophthalmol 2007; 245(3): 360-368.

51 Yanyali A, Nohutcu AF, Horozoglu F, Celik E. Modified grid laser photocoagulation $v$ s pars plana vitrectomy with internal limiting membrane removal in diabetic macular edema. [see comment]. Am J Ophthalmol 2005; 139(5): 795-801.

52 Gallemore RP, Jumper JM, McCuen II BW, Jaffe GJ, Postel EA, Toth CA. Diagnosis of vitreoretinal adhesions in macular disease with optical coherence tomography. Retina 2000; 20(2): 115-120.

53 Patel JI, Hykin PG, Schadt M, Luong V, Fitzke F, Gregor ZJ. Pars plana vitrectomy with and without peeling of the inner limiting membrane for diabetic macular edema. Retina 2006; 26(1): 5-13. 